\title{
Mechanical performance of cold-curing epoxy adhesives after different mixing and curing procedures
}

\author{
Julien Michels a, b, *, José Sena Cruz ${ }^{c}$, Rouven Christen ${ }^{\mathrm{d}}$, Christoph Czaderski ${ }^{\mathrm{a}}$, \\ Masoud Motavalli ${ }^{\text {a }}$ \\ a Structural Engineering Research Laboratory, Swiss Federal Laboratories for Materials Science and Technology (Empa), 8600, Dübendorf, Switzerland \\ ${ }^{\mathrm{b}}$ re-fer AG, 6440, Brunnen, Switzerland \\ ${ }^{\mathrm{c}}$ ISISE, Department of Civil Engineering, University of Minho, 4800-058, Guimarães, Portugal \\ ${ }^{\mathrm{d}}$ Interstaatliche Hochschule für Technik, 9471, Buchs, Switzerland
}

\section{A R T I C L E I N F O}

\section{Article history:}

Received 3 March 2016

Received in revised form

25 April 2016

Accepted 23 May 2016

Available online 26 May 2016

\section{Keywords:}

Thermosetting resins

Strength

Porosity

Mechanical testing

\begin{abstract}
A B S T R A C T
This paper presents strength, stiffness, and porosity characteristics of commercially available cold-curing epoxy adhesives for structural engineering applications in the field of externally bonded and/or nearsurface mounted composite strip reinforcements. Depending on specific requirements, accelerated curing of the adhesive under high temperatures might be necessary. Experimental investigations aimed at assessing the possible differences in strength and stiffness between samples cured at elevated temperatures for a defined time span and the ones cured at room temperature. It could be demonstrated that for the same specimen age, nominal tensile strength and stiffness are lower after an initial accelerated curing process at elevated temperatures. Furthermore, it could be shown that the specimens after an accelerated curing at elevated temperatures exhibited an increased porosity. The development of a numerical code for image analysis allowed a detailed inspection of several fracture surfaces and subsequently to assess the level of decrease in available cross-section due to an increased overall porosity. Cross-section area losses in the range of 10-15\% compared to the reference specimens could be deduced. The subsequent derivation of the actual tensile strength exhibits smaller differences between the room and high temperature exposed specimens while curing. Regardless of the short-term material strength, the observed porosity might be subject of important durability issues on a long-term and needs further investigation.
\end{abstract}

() 2016 Elsevier Ltd. All rights reserved.

\section{Introduction}

In civil engineering applications, cold-curing or low-temperature adhesives are used for bonding Carbon Fiber Reinforced Polymer (CFRP) strips to concrete with the aim of upgrading the structure's load carrying capacity [2-5]. The designation (cold-curing) refers to the fact that these resins cure under ambient temperature after the different components have been mixed. Generally, each specific epoxy product has a more or less defined 'pot-life', after which the viscosity drastically increases and thus prevents a proper workability and a proper bond to the substrate. For practical applications

\footnotetext{
* Corresponding author. Structural Engineering Research Laboratory, Swiss Federal Laboratories for Materials Science and Technology (Empa), 8600, Dübendorf, Switzerland.

E-mail address: julien.michels@empa.ch (J. Michels).
}

in structural retrofitting, operators generally prefer to stay below $25{ }^{\circ} \mathrm{C}$ in order to avoid difficulties during the installation process. After a proper epoxy mixing and application, the necessary curing duration for a sufficient bond strength and hence an adequate stress transfer under load is also highly depending on the outer temperature. Investigations by Moussa et al. [6] on cold-curing commercially available adhesives showed that significant differences in strength and stiffness developments are observed when operating at low temperatures $\left(5-10^{\circ} \mathrm{C}\right)$ compared to higher values above $25^{\circ} \mathrm{C}$. Especially at $0{ }^{\circ} \mathrm{C}$, no curing was possible anymore.

Inversly, the necessary curing duration for an epoxy adhesive to develop a sufficiently high strength for force transfer can be substantially shortened under elevated temperature. For instance, in Michels et al. [7] the influence of different curing conditions (room temperature and accelerated curing under high temperatures of about $90^{\circ} \mathrm{C}$ ) on the glass transition temperature was experimentally investigated on three different commercially available epoxies. 
A significantly higher glass transition temperature was observed in case accelerated curing was performed, thus indicating its benefical effect. Whereas curing generally occurs under ambient temperatures and takes often at least $24 \mathrm{~h}$ prior to being able of any force transfer, some application techniques even require an accelerated curing procedure at elevated temperature. The so-called 'gradient anchorage' [1,8-17], foresees a segment-wise, gradual prestress force decrease at both strip ends. The used epoxy adhesive is cured at high temperatures for about half an hour in order to exhibit a faster strength and stiffness development and thus be able to repeat a gradual force decrease at the strip ends in a sufficiently short time with regard to the pot life. Several investigations on laboratory-scale level have been carried out at Empa over the last years. Lap-shear and prestress-force releasing tests have documented the optimized heating durations for accelerated curing in order to reach the highest anchorage resistances for a specific bond length $[11,18]$. Structural efficiency of prestressed CFRP strips with gradient anchorage also has been demonstrated with application on several large-scale reinforced or prestressed concrete $[14,19,20]$.

This paper presents a study on how the mechanical performances, namely the unidirectional tensile strength $f_{a, u}$ as well as the elastic modulus $E_{a}$ are affected when cold-curing adhesives are subjected to accelerated curing at high temperatures compared to curing at ambient temperatures. The idea for the presented investigation results from several observations made on the test object of the cited references after testing. Higher porosity of the epoxy adhesive after accelerated curing was apparent. Even though the short-term structural efficiency was satisfying, durability issues should never be neglected. The goal of the presented tests is to quantify both tensile strength and stiffness after different curing procedures and ages as well as to assess the porosity of the used specimens by means of a self-developed analysis tool with a commercial programming environment (Matlab).

\section{Materials, specimens and test setup}

\subsection{Materials}

In the present investigation, three commercial epoxy adhesives, namely S\&P Resin 220, Sikadur 30 and Sikadur 30 LP (Long Pot), are investigated. All three products are two-component thixotropic materials most commonly used for bonding carbon fiber reinforced polymer (CFRP) strips on concrete, steel, or timber. Several material characteristics are listed in the respective product data sheets [21-23]. All three products are commonly used in Europe for structural retrofitting purpose.

\subsection{Specimen preparation and curing configuration}

Specimens were prepared in a teflon mould in which the mixed epoxy is filled in. They had a length of $185 \mathrm{~mm}$ and a thickness $t$ of $5 \mathrm{~mm}$ in a dogbone shape. The small test width $b$ was $10 \mathrm{~mm}$ (see Fig. 1). In total, 12 series with each time 6 specimens were tested with one specific epoxy type after different curing conditions. Table 1 summarizes the preparation and curing characteristics of the different series. Mainly the following two differences have to be pointed out:

- The first difference lies in the curing conditions. While some specimens were cured under room temperature (RT) at $21{ }^{\circ} \mathrm{C}$ (the adhesive temperature $T_{a}$ was in this case also about $21^{\circ} \mathrm{C}$ ) for 1,3 , or 7 days, the other series underwent accelerated curing (AC) during a time span of $t_{a c c}$ of $25 \mathrm{~min}$ at about $T_{a}=90^{\circ} \mathrm{C}$ $[1,11,18]$. These specimens subsequently underwent additional curing at room temperature for a determined duration prior to

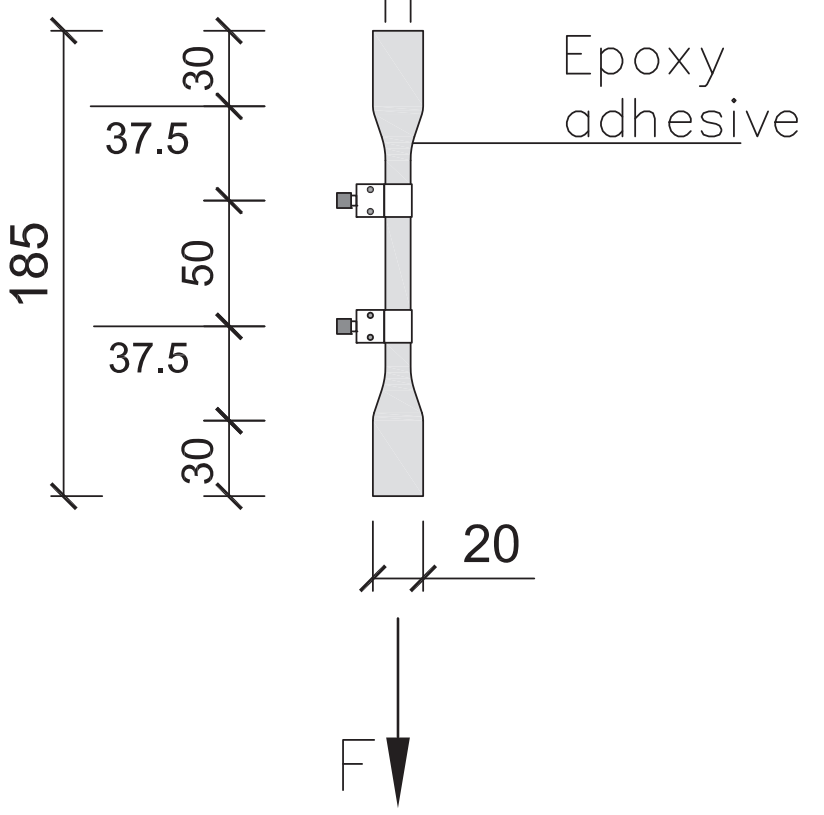

Fig. 1. Specimen dimensions [mm], Michels et al. [1].

Table 1

Mixing and curing characteristics of the tested series.

\begin{tabular}{lllll}
\hline Series & Epoxy type & Vacuum mixing & Curing & (Post-) curing time \\
\hline 1 & S\&P 220 & No & AC + RT & 30 min \\
2 & S\&P 220 & No & AC + RT & 1 day \\
3 & S\&P 220 & No & AC + RT & 3 days \\
$3 \mathrm{~V}$ & S\&P 220 & Yes & AC + RT & 3 days \\
4 & S\&P 220 & No & RT & 1 day \\
5 & S\&P 220 & No & RT & 3 days \\
6 & S\&P 220 & No & RT & 7 days \\
6 V & S\&P 220 & Yes & RT & 7 days \\
7 & Sikadur-30 & No & RT & 3 days \\
8 & Sikadur-30 & No & AC + RT & 1 days \\
9 & Sikadur-30 LP & No & AC + RT & 30 min \\
10 & Sikadur-30 LP & No & AC + RT & 1 day \\
\hline
\end{tabular}

testing. For the specimens that underwent $\mathrm{AC}$, curing time is through the whole paper indicated with the addition '(Post-)', meaning the duration from the start of cooling on until the test. Both temperature evolutions are presented in Fig. 2 (x-axis not scaled). Background of this configuration is the earlier mentioned gradient-anchorage technique for externally bonded CFRP strips in concrete strengthening.

- The second differentiation is made between mixing under a) ambient conditions and b) mixing under vacuum. The vacuum procedure was adopted in order to minimize air inclusion in the final mixture. The used vacuum mixer is presented in Fig. 3.

\subsection{Test setup}

The ISO 527-2:1993(E) standard [24] was followed in order to test the tensile properties. The setup presented in Fig. 4 . The tests 


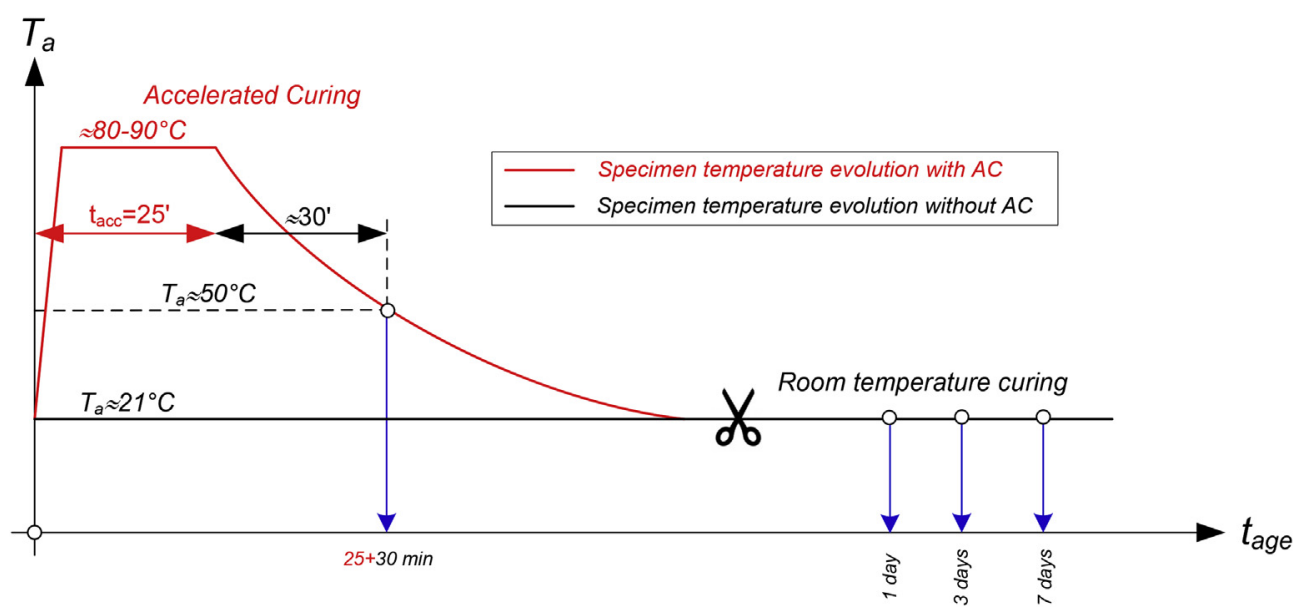

Fig. 2. Evolution of specimen temperature $T_{a}$ in time and final testing age. $t_{\text {age }}$.
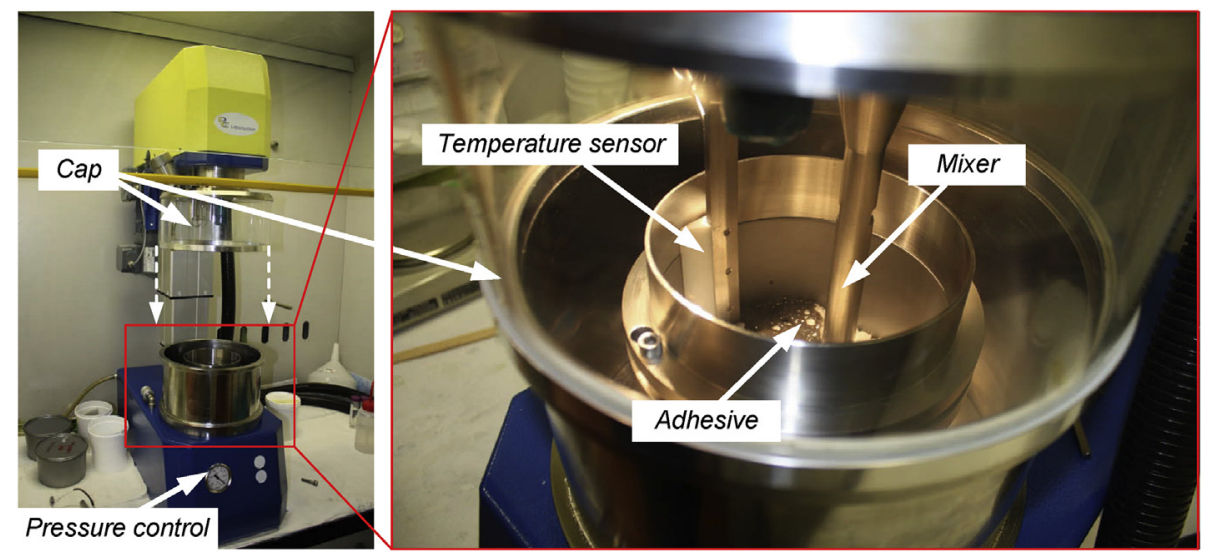

Fig. 3. Vacuum mixer.

were performed under controlled displacement at a velocity of $1 \mathrm{~mm} / \mathrm{min}$ in a servo-controlled machine (type 'Zwick/Roell Z020'). A clip gauge with a base length of $50 \mathrm{~mm}$ (accuracy class of 0.5 , according to ISO 9513:1999 [25]) was mounted at the middle of each specimen for evaluating the strain during the test (see Figs. 1 and 4 ). A load cell with $20 \mathrm{kN}$ of maximum capacity (accuracy class of 1, according to ISO 7500-1:2004 [26]) was used to measure the

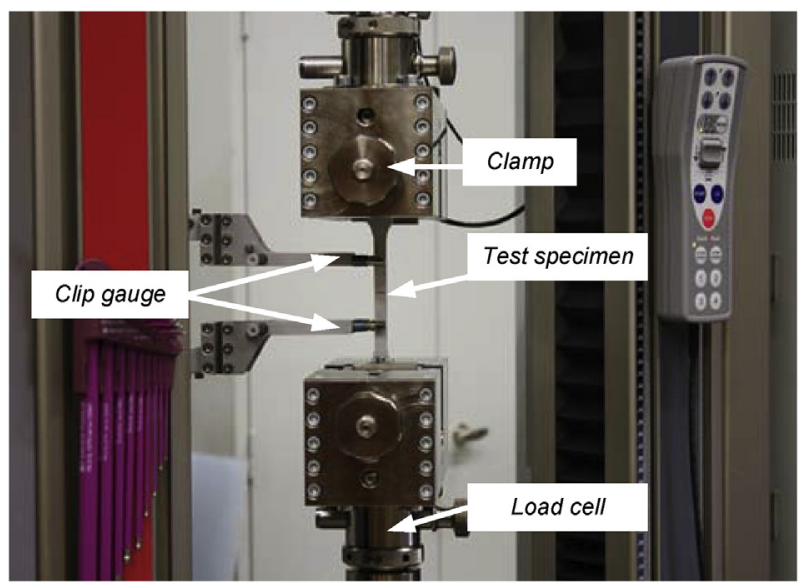

Fig. 4. Photo of the test setup. applied forces. Prior to the tensile tests, the geometry of all the specimens was assessed using a digital caliper. The thickness $t$ and width $b$ were measured at the top, middle and bottom section (Fig. 6).

\subsection{Failure surfaces and microscopic analysis}

For each test series, the specimen exhibiting strength value the closest to the serie's average strength was taken for a more detailed inspection of the fracture surface. Prior to taking microscope photographies, all retained specimens were placed in a special mould filled with a transparent resin (Fig. 5). Subsequently, with the aim to dispose of a suitable surface for the microscope photography, the surfaces were grinded in the end. The aim of the investigation was to obtain first qualitative information about how the accelerated curing at high temperatures affected the epoxy's appearance.

\section{Results and discussion}

\subsection{Experimental results}

Tensile stresses $\sigma_{a}$ and ultimate strength $f_{a, u}$ are nominal values and obtained by dividing the failure load $F_{u}$ by an average crosssection area $A_{\text {avg }}$ (Eqs. (1) and (2)), representing the mean value of the measured areas $A_{1}, A_{2}$, and $A_{3}$ presented in Fig. 6 (Eq. (3)). Strains $\varepsilon_{a}$ are evaluted by dividing the clip gauge's measured 

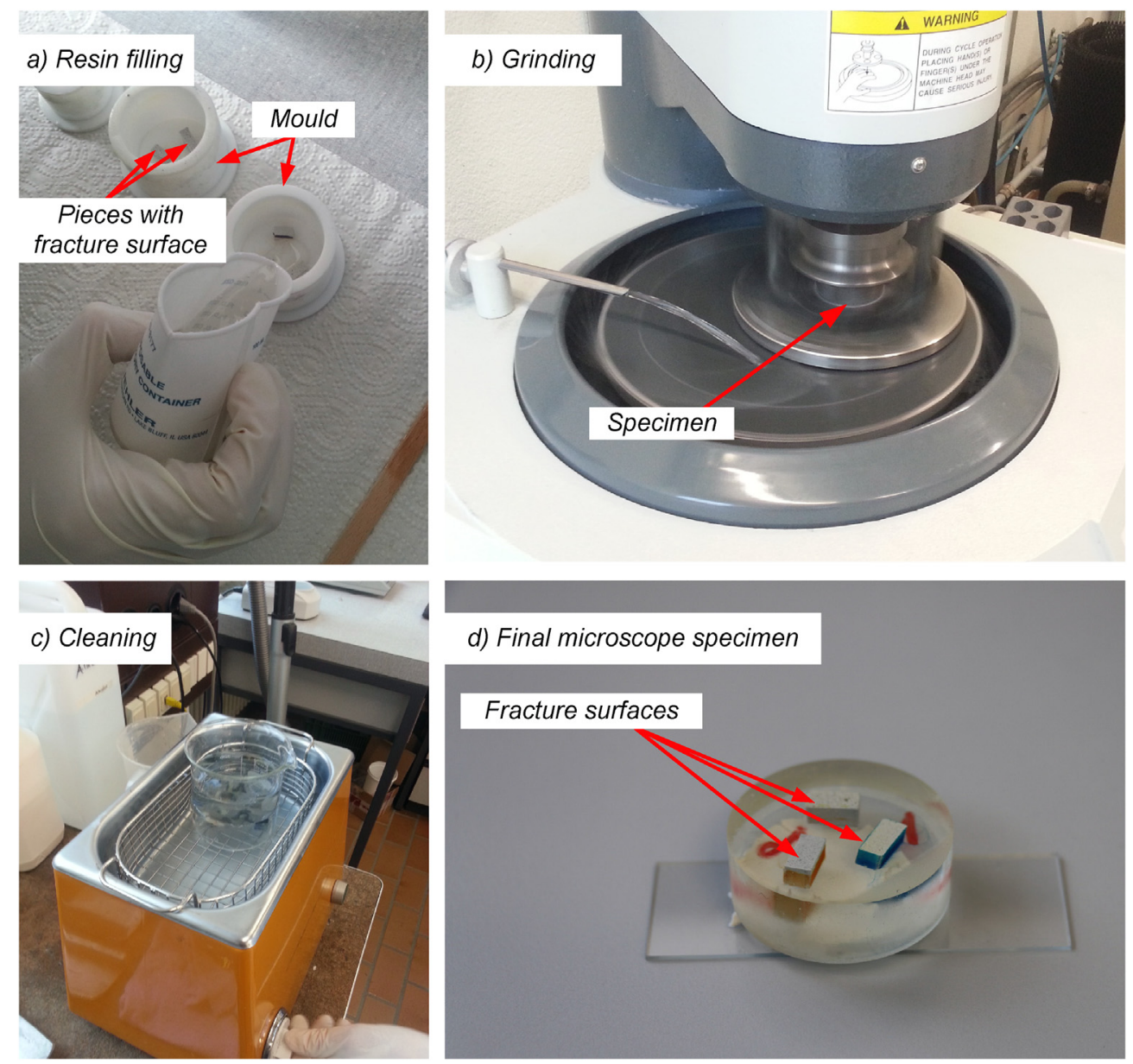

Fig. 5. Microscope specimen preparation.

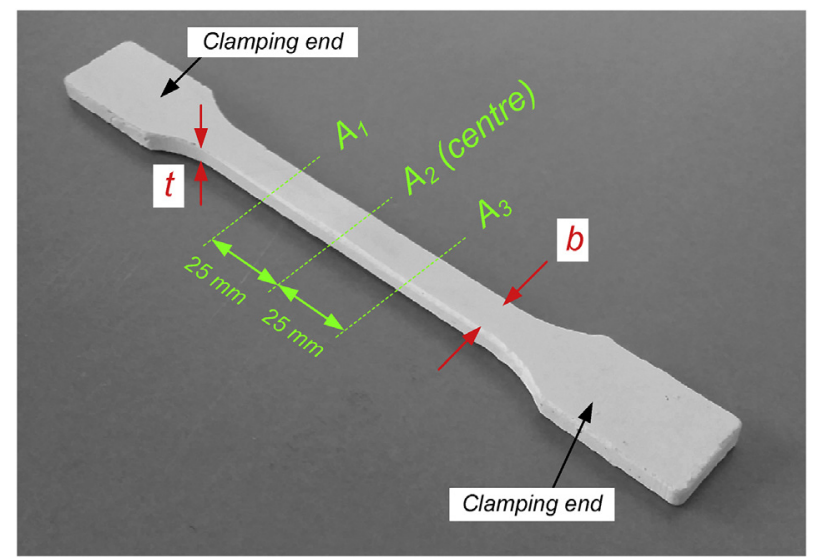

Fig. 6. Locations of the measured cross sections $A_{1}, A_{2}$, and $A_{3}$ for the tensile test dogbone specimens.

displacement by the base length of $50 \mathrm{~mm}$.

$$
\begin{gathered}
\sigma_{a}=\frac{F_{a}}{A_{a v g}} \\
f_{a, u}=\frac{F_{a, u}}{A_{a v g}}
\end{gathered}
$$

$$
A_{\text {avg }}=\frac{\sum_{i=1}^{3} A_{i}}{3}
$$

The elastic modulus $E_{a}$ is evaluated according to the ISO $527-2: 1993$ (E) [24]. It is suggested to evaluate the secant modulus between strains of 0.05 and $0.25 \%$. In this case, however, since for some specimens maximum strains lower than $0.25 \%$ were observed, a maximum of $0.15 \%$ was taken into account [1].

Stress-strain $\left(\sigma_{a} \varepsilon_{a}\right)$ diagrams of the different tensile test series with all three resins are shown in Figs. 7 and 8, respectively. The resulting average tensile strengths $f_{a, u}$ and elastic modulus $E_{a}$ values are given in Table 2 . Their evolution in function of time is presented in Fig. 9. A direct comparison of average values of all series performed with S\&P Resin 220 (Series 1-6 V) are summarized in Fig. 10. For series 3, 4, and 5, strength and stiffness evaluation has been performed with a slightly rediced number of specimens due to a very strong deviation from the series average. These specimens (two specimens for Series 4 and one specimen for Series 4 and 5) have been marked on the graphs in Fig. 7.

A first result is a distinct strength and stiffness development of the epoxy resin after an initial exposure at high temperatures. After an additional $30 \mathrm{~min}$ at room temperature, an average strength of $12 \mathrm{MPa}$ and 19.8 MPa for the S\&P Resin 220 and Sikadur 30 LP, respectively, can be obtained. The corresponding elastic moduli are 4.8 GPa and 8.3 GPa. Secondly, a uniaxial tensile strength increase with an ongoing curing duration at room temperature can be observed. The same is valid for the elastic modulus. Both curing 


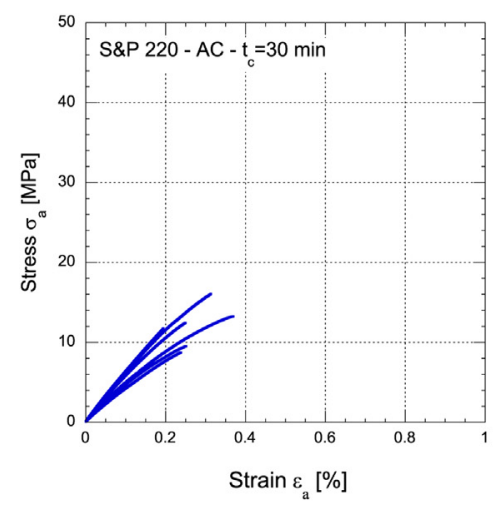

(a) Series 1

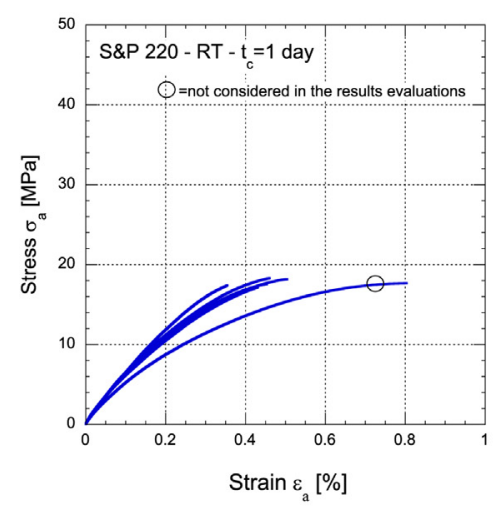

(d) Series 4

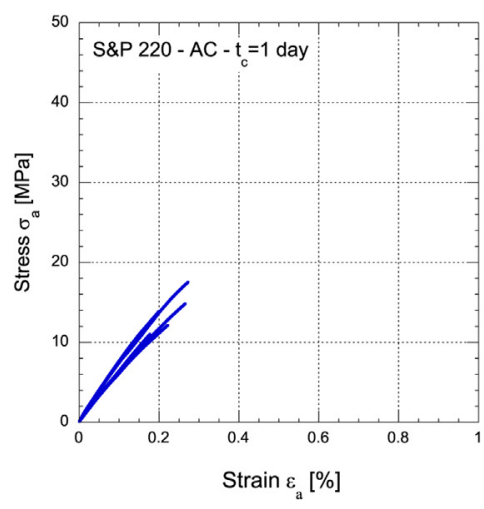

(b) Series 2

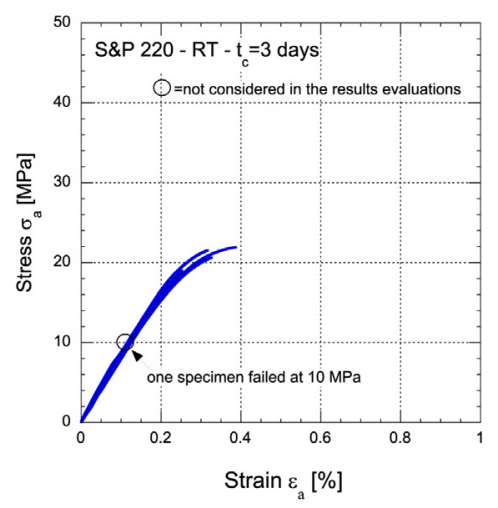

(e) Series 5

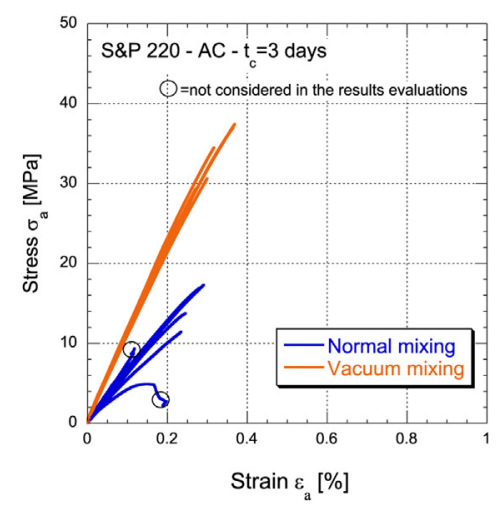

(c) Series $3+3 V$

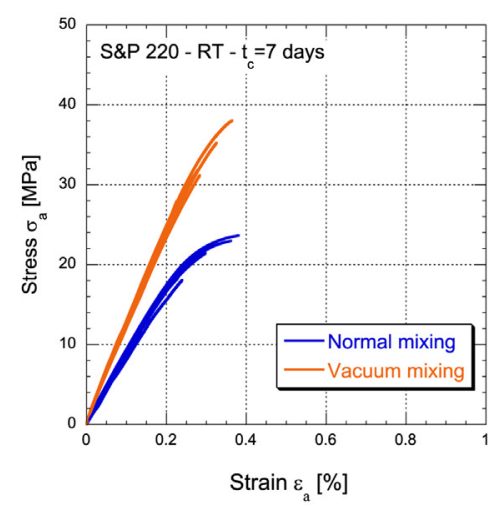

(f) Series $6+6 \mathrm{~V}$

Fig. 7. Stress-strain diagrams for S\&P Resin 220 under different curing conditions (series number according to Tables 1 and 2 ).

categories (RT and AC) show the same tendency, with a less stronger pronunciation for the specimens that underwent an initial accelerated curing. This strength increase, however, moves asymptotically towards a limit value after a certain time span. This is in accordance to the observations presented in Czaderski et al. [11], where the necessary time span to reach the ultimate strength under different temperatures is investigated for the S\&P Resin 220. Similar conclusions are presented in Moussa et al. [6] and Granja et al. [27]. Lapique and Redford [28] also come to similar conclusions, showing that for the specific epoxy used in their study, 28 days of curing at room temperature are necessary to reach the same tensile strength as after only $4 \mathrm{~h}$ at $64^{\circ} \mathrm{C}$. The reader is also invited to consult experimental investigations by Moussa et al. [29] on long-term strength development after post-curing. For the epoxy type S\&P Resin 220 cured at room temperature, the following Eq. (4) for an autocatalytic material behavior described by Moussa et al. [6] was used to predict the strength evolution in time:

$f_{a, u}(t)=\frac{f_{0}-f_{\infty}}{1+\left(\frac{t}{t_{m}}\right)^{s}}+f_{\infty}$

$f_{\infty}$ represents the maximum tensile strength that can be reached, and was taken in this case as the value reached after 3 days ( $72 \mathrm{~h}$ ). This seems justified, since after 7 days of curing, no additional strength increase could be noticed in the tests with the S\&P Resin 220 specimens (Series 5 and 6 ). $t_{m}$ is the necessary curing time for reaching a tensile strength of $f_{\infty} / 2$. Finally, $s$ is the power determining the curve slope. The initial tensile strength $f_{0}$ is $0 \mathrm{MPa}$. By minimizing the square root of the error squares sum, an optimum value for $s$ could be found. The curve is plotted in Fig. 9 a) along with the experimental values.

At the same age, specimens of Series 1 to 6 (S\&P Resin220) that previously underwent accelerated curing eventually show lower final nominal tensile strength. Similar results, but less pronounced are presented in Czaderski et al. [11]. A closer look to Table 2 and Figs. 7 and 8 reveals that the dispersion of the results seems on average a bit higher for specimens with an initial accelerated curing than for the ones fully cured at room temperature. This observation could be attributed to a higher randomness of cross-linking at higher temperature. Furthermore, for S\&P Resin 220 tests, the specimens only cured at room temperature exhibit a slightly less brittle behavior towards the ultimate strength with a progressive decrease in stiffness. This reflects as well in higher ultimate strains for the specimens purely cured at room temperature. Among the latter, 3 or 7 days of curing results in a clearly higher initial stiffness together with a lower ultimate strain at failure compared to the specimens that are 1 day old. Similar experimental results are given by Granja et al. [27].

When comparing both Sikadur 30 resins to the S\&P 220, it becomes obvious that the latter exhibits clearly lower strength values. As shown in Table 2 for a purely room temperature curing, Series 7 (Sikadur 30) shows an average ultimate tensile strength after 3 days of 24.4 MPa, whereas Series 5 (S\&P Resin 220) only offers $20.6 \mathrm{MPa}$ of tensile capacity. The same observation is made for initially accelerated curing. Whilst Series 8 (Sikadur 30) and 10 (Sikadur $30 \mathrm{LP}$ ) exhibit strength values of 27.6 and $23.8 \mathrm{MPa}$, respectively, Series 2 (S\&P Resin 220) is limited to $13.3 \mathrm{MPa}$. Similar evolution of 


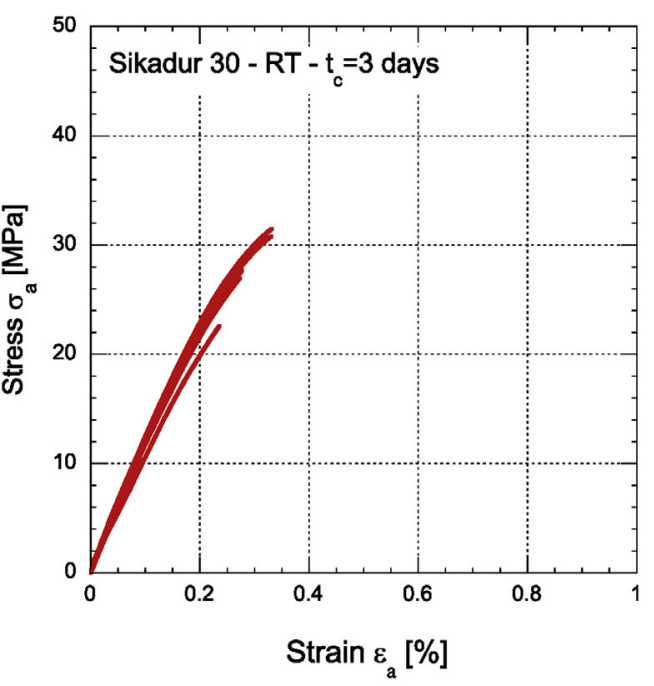

(a) Series 7

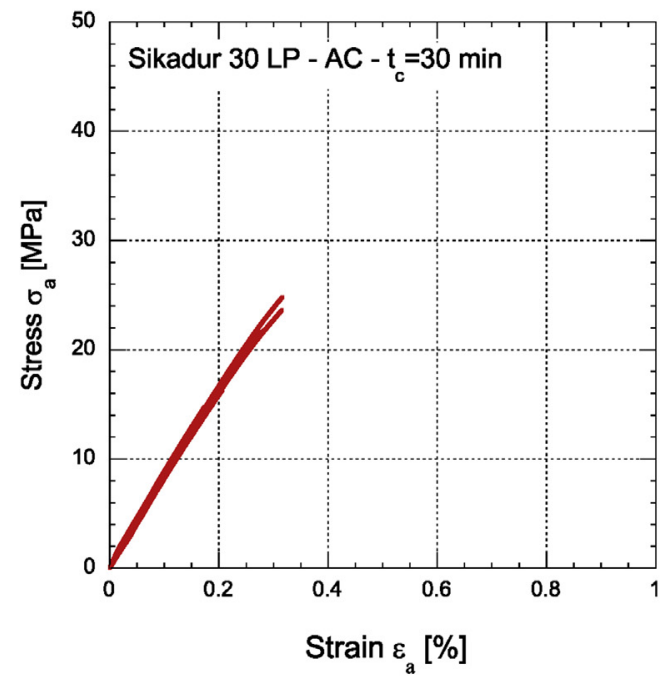

(c) Series 9

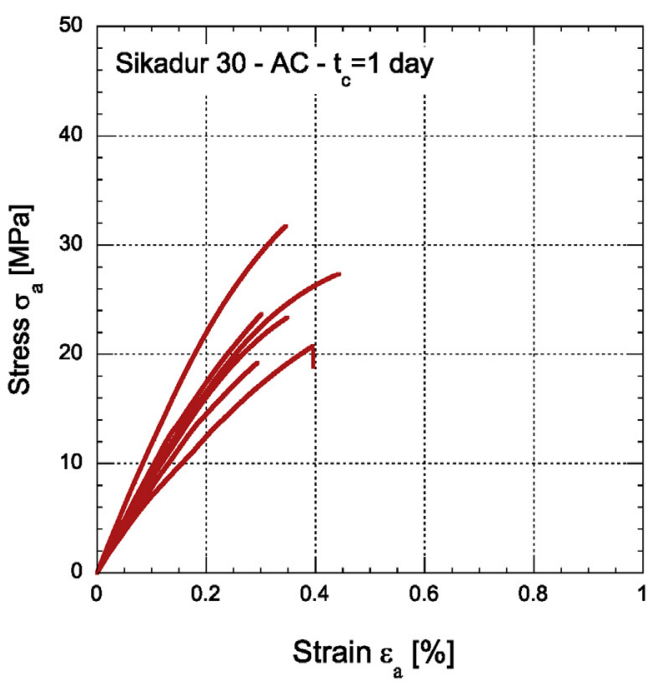

(b) Series 8

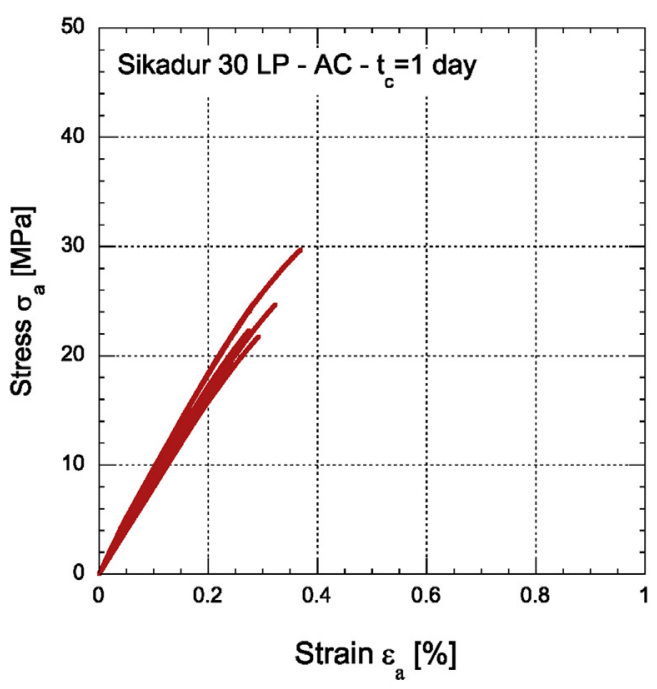

(d) Series 10

Fig. 8. Stress-strain diagrams for Sikadur 30 and Sikadur 30 LP under different curing conditions (series number according to Tables 1 and 2).

Table 2

Nominal average tensile strength $f_{a, u}$ and average elastic modulus $E_{a}$ for each series (s.d. = standard variation, C.o.V. $=$ coefficient of variation $)$.

\begin{tabular}{llllclc}
\hline Series & $f_{a, u}[\mathrm{MPa}]$ & s.d. [MPa] & C.o.V. [\%] & $E_{a}[\mathrm{GPa}]$ & s.d. [GPa] & C.o.V. [\%] \\
\hline 1 & 12.0 & 2.6 & 22 & 4.8 & 0.9 & 19 \\
2 & 13.3 & 2.7 & 20 & 6.1 & 0.5 & 9 \\
3 & 14.8 & 2.8 & 19 & 5.8 & 0.6 & 10 \\
$3 \mathrm{~V}$ & 32.4 & 4.8 & 15 & 10.9 & 0.4 & 3 \\
4 & 17.7 & 0.4 & 3 & 5.0 & 0.5 & 9 \\
5 & 20.6 & 1.2 & 6 & 7.9 & 0.1 & 1 \\
6 & 20.7 & 2.3 & 11 & 8.7 & 0.5 & 6 \\
$6 \mathrm{~V}$ & 29.6 & 7.6 & 26 & 12.0 & 0.5 & 4 \\
7 & 24.4 & 4.6 & 19 & 8.2 & 1.7 & 21 \\
8 & 27.6 & 3.3 & 12 & 10.9 & 0.5 & 4 \\
9 & 19.8 & 4.2 & 21 & 8.3 & 0.4 & 4 \\
10 & 23.8 & 3.6 & 15 & 8.5 & 0.7 & 8 \\
\hline
\end{tabular}

the materials' elastic moduli are visible.

A last interesting observation is a drastically higher tensile strength and stiffness in case the mixing of the two-component resin S\&P Resin 220 takes places in a vacuum mixer. Fig. 7 c) and f) present comparisons after 3 and 7 days of room temperature curing. Series $3 \mathrm{~V}$ has a 2.2 times higher tensile strength than the corresponding Series 3 with no vacuum mixing. In case of Series $6 \mathrm{~V}$ compared to Series 6 , the increase factor is 1.4. Similar enhancements could be observed for the stiffness with factors of 1.9 and 1.4 for both Series 3 (and $3 \mathrm{~V}$ ) and 6 (and $6 \mathrm{~V}$ ), respectively.

\subsection{Porosity and actual strength}

\subsubsection{Visual inspection of the failure surfaces}

For each test series as referred before, the test specimen exhibiting the tensile strength value the closest to the average series value $f_{a, u}$ was taken for further investigation regarding the 


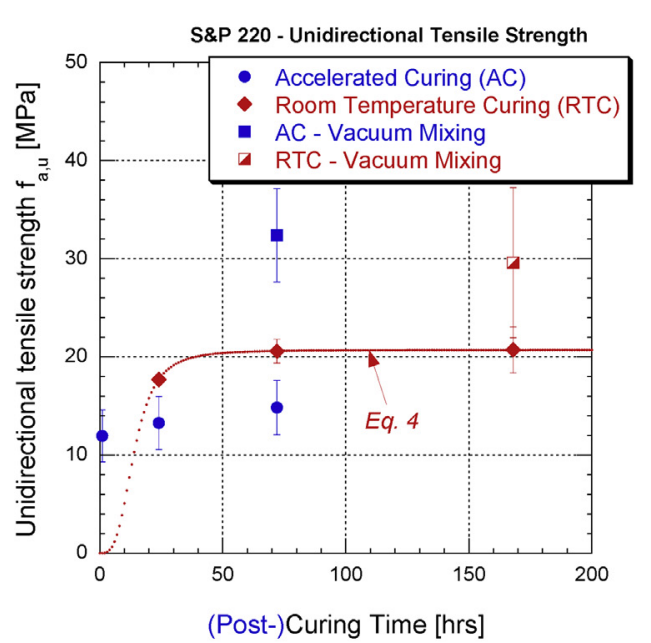

(a) Tensile strength - Series 1 to $6 \mathrm{~V}$

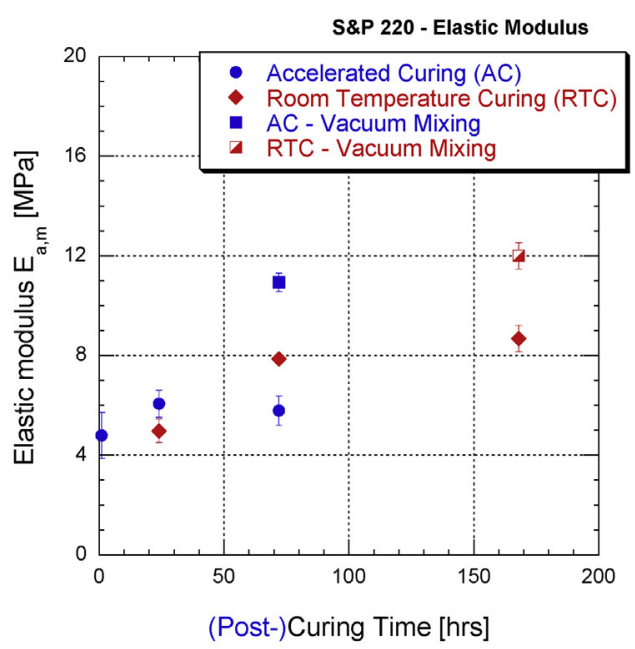

(b) Elastic modulus - Series 1 to $6 \mathrm{~V}$

Fig. 9. Tensile strength and elastic modulus in function of the (post-) curing time.

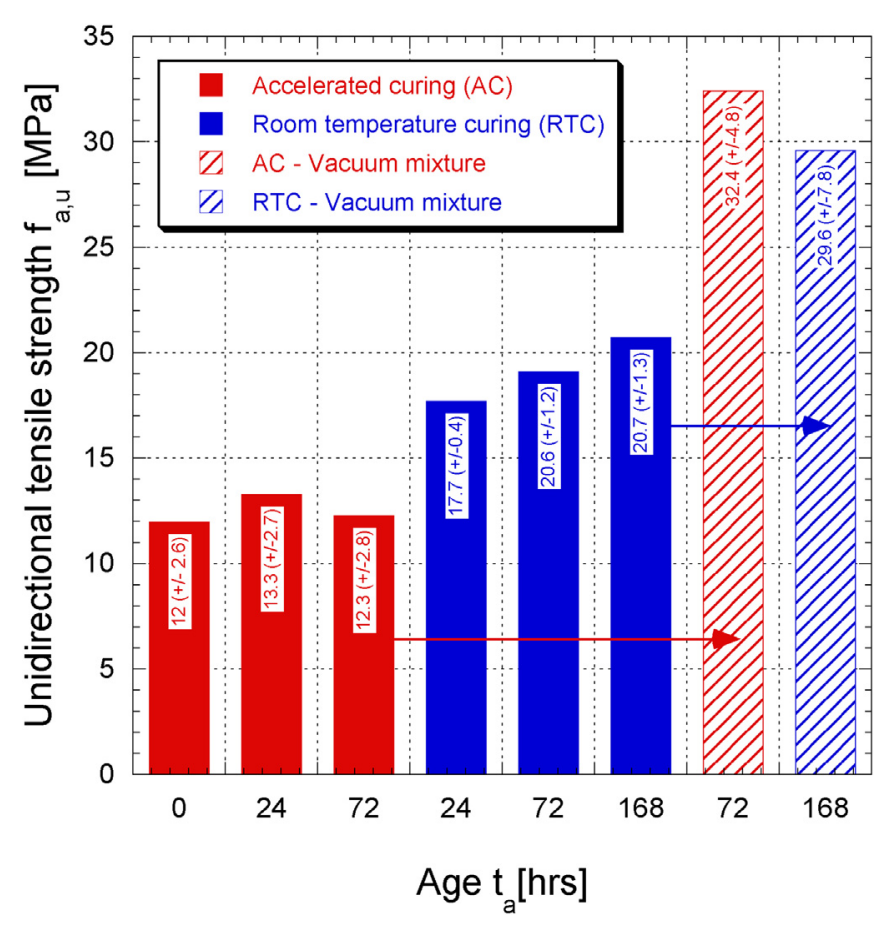

Fig. 10. Average strength values for S\&P Resin 220 specimens in relation to the curing type and duration.

porosity. Microscope photos of series are given in Fig. 11. When qualitatively investigating the microscope photos for Series 1 to 3 and 8 , it becomes obvious that porosity has drastically increased when high temperature is initially applied to the uncured epoxy (Series 9 and 10 both underwent accelerated curing, and no reference specimen has been tested). Regarding product differences, it seems that Sikadur 30 and Sikadur 30 LP (Series 8 to 10) exhibit less porosity than the corresponding tests with S\&P Resin220 (Series 1 to 3). Mixing the epoxy resin under vacuum, however, strongly reduces if not almost annihilates the porosity devlopment. When comparing the photos for Series 3 and $3 \mathrm{~V}$ (accelerated curing) as well as 6 and $6 \mathrm{~V}$ (room temperature curing), respectively, the effect is obvious. This characteristic might be related to two different reasons: i) Using an automatic mixer under vacuum prevents including ambient air into the final mix (see photos of Series 4, 5, and 6), ii) A small smoke-like evaporation appearance at the moment of the vacuum application was observed and could indicate the escape of a component. Since Series $6 \mathrm{~V}$ did not undergo accelerated curing and was not influenced by an increased porosity, this component might be partially responsible for the increase in porosity when no vacuum mixing is performed. The accelerated curing with this type of epoxy material without any vacuum mixing might provoke the evaporation of this volatile component. However, due to the restraint boundary conditions in the mould, the evaporation is prohibited and thus results in an increased porosity.

\subsubsection{Actual strength values}

A Matlab-based code was established in order to evaluate the relative loss of cross-section area due to an accelerated curing at high temperatures. Fig. 12 presents the summarized procedure that was followed on one specimen's fracture surface. The code loads the initial microscope image, and subsequently the user has to manually perform a first brightness adjustment. The photo in Fig. 12 b) now contains the pores as well as some darker pigments from the epoxy matrix. These are in their totality smaller than the pores. Additionally, they also exhibit a much more irregular shape than the more circular/elliptical appearance of the real voids. Hence, in a second step, additional shape and size excluding criteria based on combined probability are implemented. The photo shown in Fig. $12 \mathrm{c}$ ) represents the finally retained section for the evaluation of the pore ratio in section $\rho$. It is emphasized that the evaluation technique contains several criteria, for which setting the treshold values (brightness, shape, size) required the personal engineering judgement of the operator. Each specimen analyzed had to be treated separately and the graphic results analyzed in a careful manner, no fully automatic procedure was established.

Table 3 presents the results of the effective tensile strength derivation by the previously presented fracture surface analysis. For instance, the area of the pores $A_{\text {pores,tr }}$ after the first brighness treshold is shown together with the final pores area $A_{\text {pores }}$ obtained after including the shape and size criteria. Since only the fracture surface and not the complete specimen volume was investigated, nominal tensile strength of the considered specimen $f_{a, u, s p}$ is in this case deducted by dividing the ultimate load $F_{u, s p}$ by the complete fracture surface section $A_{\text {tot }}$, opposite to the averaging technique 

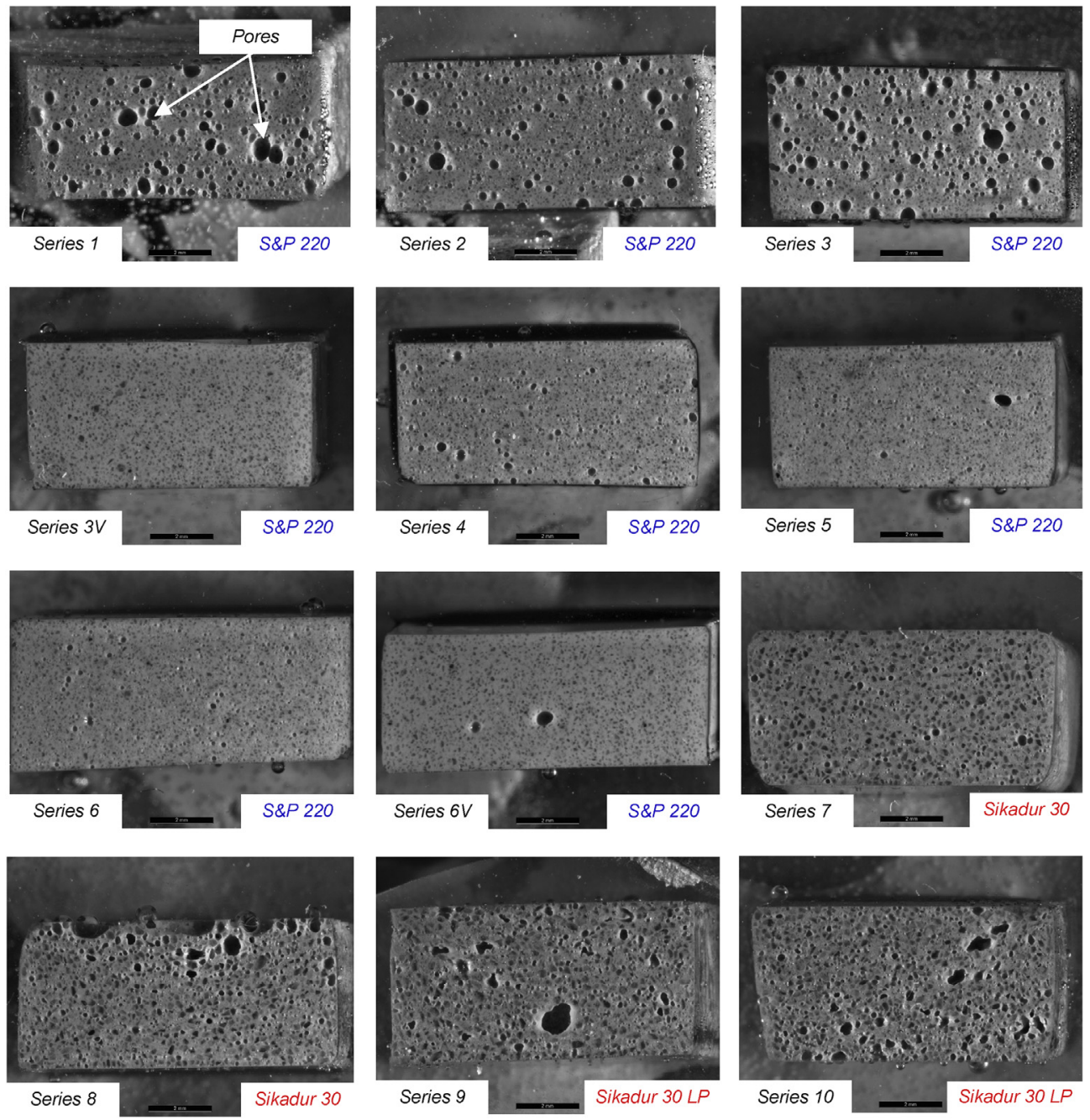

Fig. 11. Microscope photos of one failure cross section for each series.

earlier presented in Section 3.1 (Eqs. (2) and (3)). The final effective tensile strength is then deducted by dividing the ultimate load $F_{u, s p}$ by the reduced surface $A_{\text {tot }}-A_{\text {pores }}$. Table 3 and Fig. 13 show the results for the different categories. The pores ratio in section $\rho$ is obtained by evaluating $A_{\text {pores }} / A_{\text {tot }}$. First of all, it is visible in Table 3 and Fig. 13 that conventional mixing by hand a subsequent curing at room temperature resulted in porosity ratios between 2.5 and $3.5 \%$. If the mixing is performed under vacuum, however, porosity can be reduced to approximately $0.5 \%$. Furthermore, if an accelerated curing at elevated temperatures is performed prior to an additional room temperature curing, pore ration cleary increases up to values between 12 and 17\% for resin types S\&P Resin 220 and Sikadur 30 , and to about $9.5 \%$ for Sikadur $30^{\circ} \mathrm{LP}$. Independently if a nominal or effective value is considered, mixing under vacuum results in drastic strength increases by a factor about 2 and 1.6 for an accelerated or full room temperature curing, respectively. In terms of pore presence, the results confirm what has been previously described in a qualitative manner in Section 3.2.1. Accelerated curing involved a clearly reduced cross-section area compared to the reference tests due to an increased presence of voids. This increased porosity is on average more pronounced for S\&P Resin 220 and Sikadur 30 specimens than for Sikadur 30 LP samples. The differences in effective strength values are less pronounced than in case of nominal values (see Fig. 14). A suprising observation is the fact that the effective strength $f_{a u, e f f}$, taking into account the reduced cross-section area due to the porosity, is lower for specimens that underwent an initial acceleratee curing compared to the ones fully cured at room temperature with the same age. This can be observed when comparing Series 2 to Series 4 (specimen age 1 day) as well Series 3 to Series 5 (specimen age 3 days). Due to a more pronounced chain cross-linking when applying an initial curing at elevated temperatures in addition to one at room temperature, one might one hand expect am improved effective tensile strength. On the other, random cross-linking might occur and hence result in a less favorable quality of the chain formation. In this case, lower strength values were observed. An additional possible explanation might be an irregular and thus unfavorable stress distribution with a more elevated porosity. The irregular cross-section could implicate stress peaks at the void tips, hence leading to a premature fracture, compared to a more even and hence favorable stress distribution over the specimen width in case no pores (or less) are present. This less homogeneous stress transfer could also be an explanation of the higher strength deviation in case of an accelerated curing, along with a possible higher randomness of cross-linking (see Section 3.1). 
a) Original microscope image

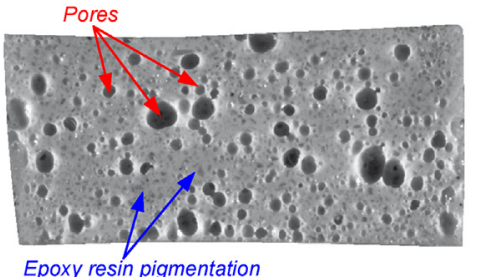

b) First brightness treshold

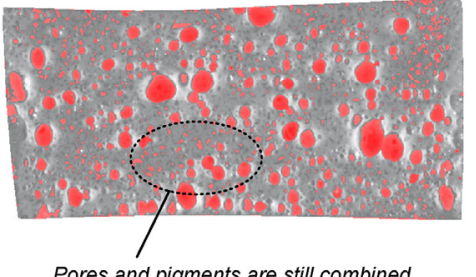

Pores and pigments are still combined

c) Final porosity image

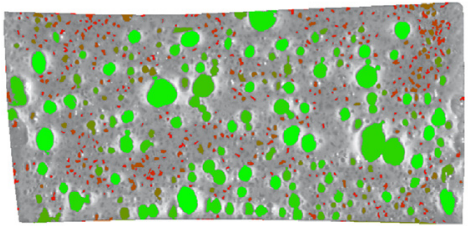

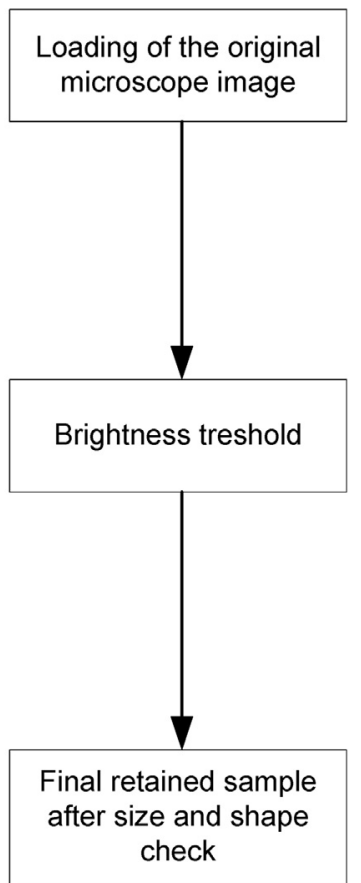

Fig. 12. Different steps during the evaluation of the pore presence in a specimen's fracture surface.

\section{Conclusions}

The presented results allow to draw a certain number of conclusions regarding the pore ratios as well as strength and stiffness development of cold-curing epoxy adhesives.

- Normal epoxy mixing by hand followed by a curing at room temperature results in porosity values between 2.5 and $3.5 \%$, measured in the failure cross-section. It is precised that the indicated values are valid for the resins tested in this study. They cannot be generalized to other cases, such as the presence of fillers for instance.

- An initial mixing of the resin components under vacuum drastically reduces the porosity ratio in the failure cross-section to

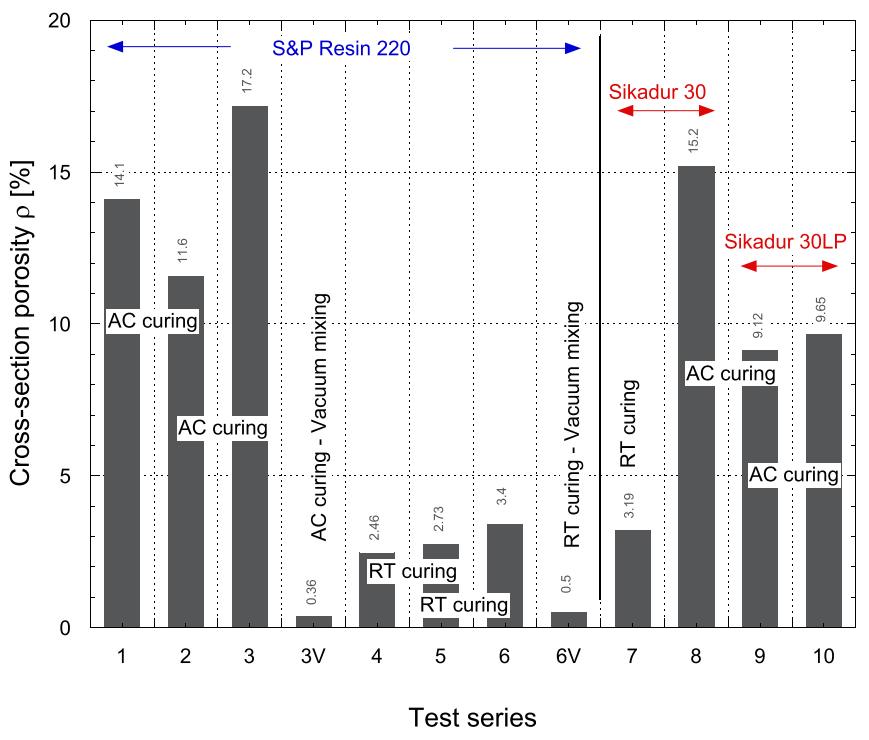

Fig. 13. Porosity ratio in the fractured sections.

approximately $0.5 \%$ for both curing procedures at room and at elevated temperature. Nominal strength increases in both cases.

- An initial epoxy exposure to high temperature of $80-90{ }^{\circ} \mathrm{C}$ for 25 min accelerates the curing and allows for a much faster strength and stiffness development. However, this accelerated curing also involves a stronger porosity of the herein investigated materials. Values for the porosity ratio in the failure section of around 9.5 and 17\% have been observed in this study, depending on the used product. Nominal strength and elastic modulus is therefore lower than the corresponding ones for specimens cured at room temperature with the same age. It was found that even the effective strength, taking into account the porosity and only calculating with a net cross-section, is also lower for the accelerated curing specimens. A reason might be a less favorable stress distribution over the cross-section due to the pores.

- The epoxy specimens cured for short periods up to 3 days showed a large scattering. This can be considered an indication that the curing process is still ongoing at that moment, and that a larger time span has to be considered for an almost full curing.

- The developed numerical code, by analyzing a photo of the failure cross section, gave the possibility to evaluate the effective tensile strength by estimating the level of porosity and hence fracture surface loss. Especially for specimens that initially

Table 3

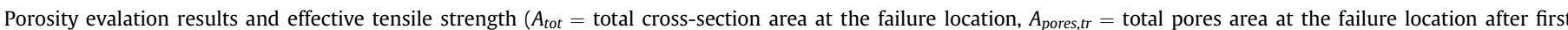

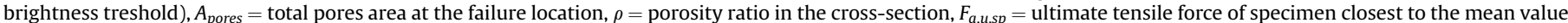
of the series, $f_{a, u, s p}=$ Nominal unidirectional tensile strength of one tensile specimen, $f_{a, u, e f f}=$ effective tensile strength of the epoxy.

\begin{tabular}{|c|c|c|c|c|c|c|c|}
\hline & $A_{\text {tot }}\left[\mathrm{mm}^{2}\right]$ & $A_{\text {pores }, t r}\left[\mathrm{~mm}^{2}\right]$ & $A_{\text {pores }}\left[\mathrm{mm}^{2}\right]$ & $\rho[\%]$ & $F_{a, u, s p}[\mathrm{~N}]$ & $f_{a, u, s p}[\mathrm{MPa}]$ & $f_{a, u, e f f}[\mathrm{MPa}]$ \\
\hline 1 & 40.89 & 8.04 & 5.76 & 14.10 & 514 & 12.6 & 14.6 \\
\hline 2 & 48.90 & 8.29 & 5.66 & 11.57 & 698 & 14.3 & 16.1 \\
\hline 3 & 46.53 & 10.55 & 7.99 & 17.16 & 648 & 13.9 & 16.8 \\
\hline $3 \mathrm{~V}$ & 42.29 & 0.25 & 0.15 & 0.36 & 1308 & 30.9 & 31.0 \\
\hline 4 & 44.39 & 1.68 & 1.09 & 2.46 & 779 & 17.5 & 18.0 \\
\hline 5 & 42.27 & 1.98 & 1.16 & 2.73 & 903 & 21.4 & 22.0 \\
\hline 6 & 51.31 & 2.97 & 1.75 & 3.40 & 1153 & 22.5 & 23.3 \\
\hline $6 \mathrm{~V}$ & 45.86 & 0.30 & 0.23 & 0.50 & 1556 & 33.9 & 34.1 \\
\hline 7 & 48.88 & 2.55 & 1.56 & 3.19 & 1392 & 28.5 & 29.4 \\
\hline 8 & 46.79 & 11.41 & 7.11 & 15.19 & 1195 & 25.5 & 30.1 \\
\hline 9 & 48.60 & 7.21 & 4.43 & 9.12 & 1083 & 22.3 & 24.5 \\
\hline 10 & 47.05 & 7.13 & 4.54 & 9.65 & 1056 & 22.5 & 24.9 \\
\hline
\end{tabular}




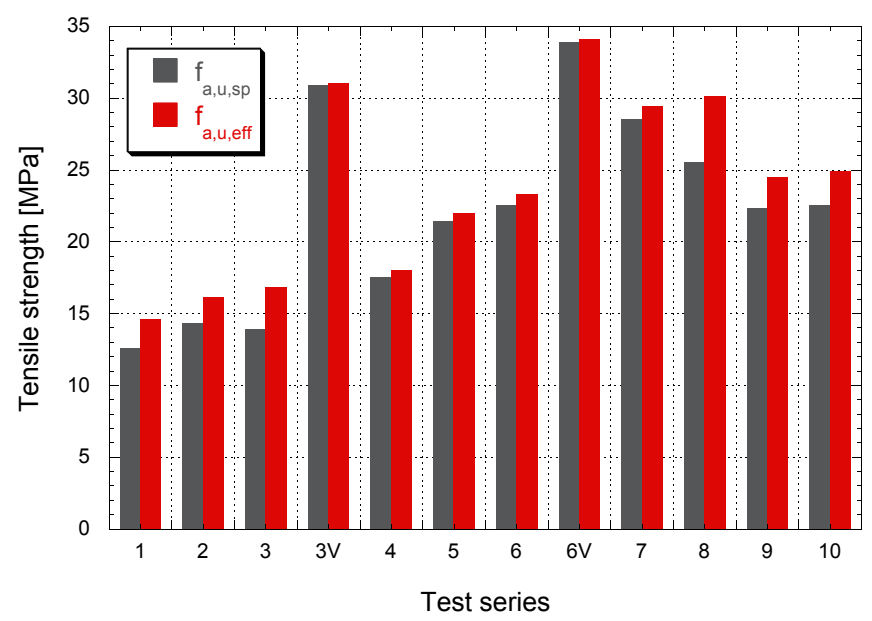

Fig. 14. Nominal and effective tensile strength of the respective test specimen for each tested series.

underwent an accelerated curing process, the effective tensile strength is clearly higher than the nominal one. The difference to the nominal strength values for room temperature cured specimens is much smaller, and almost non existant for the ones with an initial product mixing under vacuum.

- Future research should investigate the effects of an increased porosity on the durability of retrofitted structures. Especially cases for which an accelerated curing under high temperatures was applied, the increased porosity might facilitate penetration of deterioration agents and hence might considerably affect the overall long-term efficiency of the strengthening method.

\section{Acknowledgements}

The authors want to express their gratitude to Max Heusser and Milos Dimic (Empa, $\mathrm{CH}$ ) for their assistance in the experimental investigation. Marcel Rees, Iurii Burda and Andrea Battisti (Empa, $\mathrm{CH}$ ) are kindly acknowledged for their assistance with the vacuum mixer and the sample preparation for porosity assessment. Eventually, Esther Strub (Empa, CH) is acknowledged for the instructions about the miscroscope utilization. Distributors S\&P Clever Reinforcement $\mathrm{AG}(\mathrm{CH})$ and Sika $(\mathrm{CH})$ are also acknowledged for their material provision. This work is also supported by FEDER funds through the Operational Program for Competitiveness Factors COMPETE and National Funds through FCT - Portuguese Foundation for Science and Technology under the projects FRPreDur FCOMP01-0124-FEDER-028865 (FCT no. PTDC/ECM-EST/2424/2012).

\section{References}

[1] Michels J, Sena Cruz J, Czaderski C, Motavalli M. Structural strengthening with prestressed CFRP strips anchored with the gradient method. J Compos Constr 2013:17(5):651-61.

[2] Kaiser HP. Strengthening of reinforced concrete with epoxy-bonded carbonfibre plastics. 1989. PhD thesis No. 8918 (in German), ETH Zürich.

[3] Meier U. Strengthening of structures using carbon fibre/epoxy composites. Constr Build Mater 1995;9(6):341-51.
[4] Meier U. Composite materials in bridge repair. Appl Compos Mater 2000;7(2): $75-94$

[5] Bakis CE, Bank LC, Brown VL, Cosenza E, Davalos JF, Lesko JJ, et al. Fiberreinforced polymer composites for construction - state-of-the-art review. I Compos Constr 2002;6(2):73-87.

[6] Moussa O, Vassilopoulos AP, de Castro J, Keller T. Early-age tensile properties of structural epoxy adhesives subjected to low-temperature curing. Int J Adhes Adhes 2012;35:9-16.

[7] Michels J, Widmann R, Czaderski C, Allahvirdizadeh R, Motavalli M. Glass transition evaluation of commercially available epoxy resins used for civil engineering applications. Compos Part B Eng 2015;77:484-93.

[8] Meier U, Stöcklin I. A novel carbon fiber reinforced polymer (CFRP) system for post-strengthening. In: International conference on concrete repair, rehabilitation and retrofitting (ICCRRR). Cape Town, South Africa; 2005.

[9] Aram MR, Czaderski C, Motavalli M. Effects of gradually anchored prestressed CFRP strips bonded on prestressed concrete beams. J Compos Constr 2008:12(1):25-34.

[10] Kotynia R, Walendziak R, Stoecklin I, Meier U. RC slabs strengthened with prestressed and gradually anchored CFRP strips under monotonic and cyclic loading. ASCE J Compos Constr 2011;15(2):168-80.

[11] Czaderski C, Martinelli E, Michels J, Motavalli M. Effect of curing conditions on strength development in an epoxy resin for structural strengthening. Compos Part B Eng 2012;43(2):398-410.

[12] Czaderski C. Strengthening of reinforced concrete members by prestressed externally bonded reinforcement with gradient method. 2012. p. 459. PhD thesis No. 20504, ETH Zürich, http://dx.doi.org/10.3929/ethz-a-007569614.

[13] Michels J, Martinelli E, Czaderski C, Motavalli M. Prestressed CFRP strips with gradient anchorage for structural concrete retrofitting: experiments and numerical modeling. Polymers 2014;6(1):114-31.

[14] Michels J, Zile E, Czaderski C, Motavalli M. Debonding failure mechanisms in prestressed CFRP/epoxy/concrete connections. Eng Fract Mech 2014;132: 16-37.

[15] Correia L, Teixeira T, Michels J, Almeida JAPP, Sena-Cruz J. Flexural behaviour of RC slabs strengthened with prestressed CFRP strips using different anchorage systems. Compos Part B Eng 2015;81:158-70.

[16] Sena-Cruz J, Michels J, Harmanci YE, Correia L. Flexural strengthening of RC slabs with prestressed CFRP strips using different anchorage systems. Polymers 2015;7(10):2100-18.

[17] Motavalli M, Czaderski C, Pfyl-Lang K. Prestressed CFRP for strengthening of reinforced concrete structures: recent developments at Empa, Switzerland. J Compos Constr 2011;15(2):194-205.

[18] Michels J, Czaderski C, El-Hacha R, Brönnimann R, Motavalli M. Temporary bond strength of partly cured epoxy adhesive for anchoring prestressed CFRP strips on concrete. Compos Struct 2012;94(9):2667-76.

[19] Czaderski C, Motavalli M. 40-Year-old full-scale concrete bridge girder strengthened with prestressed CFRP plates anchored using gradient method. Compos Part B Eng 2007;38(7-8):878-86.

[20] Michels J, Staśkiewicz M, Czaderski C, Harmanci YE, Kotynia R, Motavalli M. Prestressed cfrp strips for bridge girder retrofitting - application and static loading test. ASCE J Bridge Eng 2016. http://dx.doi.org/10.1061/(ASCE) BE.1943-5592.0000835. accepted manuscript.

[21] S\&P-Clever-Reinforcement-Company-AG. S\&P Resin 220 epoxy adhesive technical data sheet. S\&P Clever Reinforcement Company AG; 2012.

[22] Sika. Sikadur-30 Adhesive for bonding reinforcement - product data sheet. Sika; 2006.

[23] Sika. Sikadur-30 LP Adhesive for bonding reinforcement - product data sheet. Sika; 2006.

[24] ISO-527-2. Plastics - Determination of tensile properties - Part 2: Test conditions for moulding and extrusion plastics.

[25] ISO9513. Metallic materials - Calibration of extensometers used in uniaxial testing.

[26] ISO9513. Metallic materials - Verification of static uniaxial testing machines Part 1: Tension/compression testing machines - Verification and calibration of the force-measuring system.

[27] Granja JL, Fernandes P, Benedetti A, Azenha M, Sena-Cruz J. Monitoring the early stiffness development in epoxy adhesives for structural strengthening. Int J Adhes Adhes 2015;59:77-85.

[28] Lapique F, Redford K. Curing effects on viscosity and mechanical properties of a commercial epoxy resin adhesive. Int J Adhes Adhes 2002:22(4):337-46.

[29] Moussa O, Vassilopoulos AP, Castro JD, Keller T. Long-term development of thermophysical and mechanical properties of cold-curing structural adhesives due to post-curing. J Appl Polym Sci 2013;127(4):2490-6. 